\title{
Impact of political risk on construction cost in PPP project in KSA
}

Yahya Alfraidi ${ }^{1, *}$, Saleh Mohammed Alzahrani ${ }^{2}$, Fawaz Binsarra ${ }^{3}$, Mohamed Hssan Hassan Abdelhafez ${ }^{1,4}$, Emad Mohamed Noaime ${ }^{1}$, Mohamed Ahmed Said Mohamed ${ }^{1}$

${ }^{1}$ Architecture Engineering Department, College of Engineering, Hail University, Hail, Saudi Arabia ${ }^{2}$ Civil Engineering Department, University of Business \& Technology-UBT, Jeddah, Saudi Arabia ${ }^{3}$ College of Architecture, King Saud University, Riyadh, Saudi Arabia

${ }^{4}$ Architecture Engineering Department, Faculty of Engineering, Aswan University, Aswan, Egypt

\section{ARTICLE INFO}

\section{Article history:}

Received 10 November 2019

Received in revised form

3 February 2020

Accepted 3 February 2020

\section{Keywords:}

Impact of risks

Public-private partnership

Construction cost
Political risk

\begin{abstract}
A B S T R A C T
The primary purpose of this research paper is to investigate the impact of political risk factors in the lifecycle of Public-private partnerships (PPP). Due to a large number of stakeholders in pPPP projects, the complexity of interactions between them increases which raises the importance of this study. Throughout an intensive literature review, this research paper extracted the most influential factors that impact the (PPP) projects, especially factors that impact the cost overrun, project termination, and project delay. The research methodology was applied is based on evaluating the risk factors extracted from the literature review on the probability of occurrence of the event and the size of the impact to result of the risk effect value. Data were collected from a questionnaire shared with experts in the field of construction to enhance the accuracy of the estimated risk impact. The analysis of the data gathered and the ranking of the political risk factors resulted in measures of the Risk Likelihood and Risk impact of the ten most impacting factors. The research concludes that the relationship between the impacts of risk factors is associated with the risk cost and actual construction price.
\end{abstract}

(C) 2020 The Authors. Published by IASE. This is an open access article under the CC BY-NC-ND license (http://creativecommons.org/licenses/by-nc-nd/4.0/).

\section{Introduction}

risk factors into the construction cost. Moreover, the shortage expanded in modeling the interactions and the interdependency of the political risk factors into the construction cost of certain types of projects such as PPP projects, which are tackled in this research paper. The political risk factors are the most critical aspects that affect the cost of the PPP projects due to the several reasons stated in the literature extensively. The purpose of this research is to evaluate the impact of political risk factors extracted from an intensive literature review on the factors that affect construction cost in the PPP project. factors are the drivers of increasing cost in the construction project, which caused by the influential risk factors that are investigated in this research.

Even though the field of risk management standardized the mitigation of risk impact in construction projects, there is still a shortage of a systematic approach in modeling the impact of the

\footnotetext{
* Corresponding Author.

Email Address: y.alfraidi@uoh.edu.sa (Y. Alfraidi)

https://doi.org/10.21833/ijaas.2020.05.002

(D) Corresponding author's ORCID profile:

https://orcid.org/0000-0002-8654-6797

2313-626X/C) 2020 The Authors. Published by IASE.

This is an open access article under the CC BY-NC-ND license

(http://creativecommons.org/licenses/by-nc-nd/4.0/)
}

\section{Literature review}

Political risk in construction projects can be defined as a threat to project incomes resulting from an outside impact to the project, most likely a regulatory action that affects the project or a lack of an action that impacts the project's success and progress as well. This action could be a result of regulation changes with a lack of alignment with construction phases to enhance that cost recovery. Moreover, the combination of political factors that influence the construction cost is very interrelated to economic factors that need to be differentiated then 
political factors. In order to distinguish between economic and political factors, Howell (1998) proposed the method of contemplating and observation of the incident that is surrounded by political risk factors to build up a framework that places the risk factors in categories. These categories of risk factors in construction considered with political circumstances, policy movement, and trade affiliations.

A PPP project lifespan is very long and can reach up to 30 years, which places the project at a very high risk of regulatory changes within this period. In the literature, there are significant risk factors that need to be taking into consideration for PPP projects. Political risk can accrue due to inadequate agreement between project parties, lack of accuracy in the law, and incorrect action from different organizations related to the project. In addition, Ke et al. (2010) stated that political risk could result from changes in low and regulations, not wellexplained regulations. Also, the changes in policies of the government, unjustified delays of project licensing and permits. It also added the changes in the law when the local government applies new laws and regulations. All those factors considered risk driving factors that characterized as political risk factors. In this research paper the political risk factors impacting construction project which are going to be analyzed are the risk of change in law, delay in project approval and permits, poor public decision-making process, regulator intervention, unstable regulator, accuracy of regulator, conflict in regulations, strong regulation opposition, expropriation of assets, and Inability of concessionaire.

According to Kreydieh (1996), in order to eliminate these political risk factors in construction projects, several actions need to be taking to integrate important information within the rules of the government. These important actions are establishing guarantees from regulator to protect project from impediment, receiving a legal view from the government especially for contracts, necessitating political risk insurance for all project parties, including investors from different countries and involving number of external parties in the project, and establishing accounts in specific countries to collect sales incomes from purchaser.

\section{Research methodology}

In this research, the evaluation of the risk event based on the probability of occurrence of the event and the size of its impact are investigated. Furthermore, if the probability of occurrence of a risk event in $\mathrm{P}$ and the size of its impact on the project in I, then the expected risk effect value is:

$\mathrm{EV}=\mathrm{P} \times \mathrm{I}$

The expected value of risk effect in this research represented on a scale of 1-25, and then the results are normalized between 0 and 1 . There is a lack of accurate data collected about the impact of political risk factors on the construction cost of PPP. Therefore, it is very crucial to collect this data from the field experts. In seeking this data, a questionnaire conducted to investigate and estimate the qualitative risk impact from expert judgment. The result of this questioner used to create a model that maps the political risk factors into the impact of construction cost. This model presented and analyzed using statistical methods and probability distribution for political risk factors constructed exactly using easy-fit software. These outcomes used for multiple-regression models to perform simulation using VENSIM software. The regression modeling technique was used in construction and management files to enhance the ability to predict project performance. This modeling technique is dependent on variable $\mathrm{X}$ is causing statically other variables $\mathrm{Y}$ to change. Fig. 1 shows the research methodology.

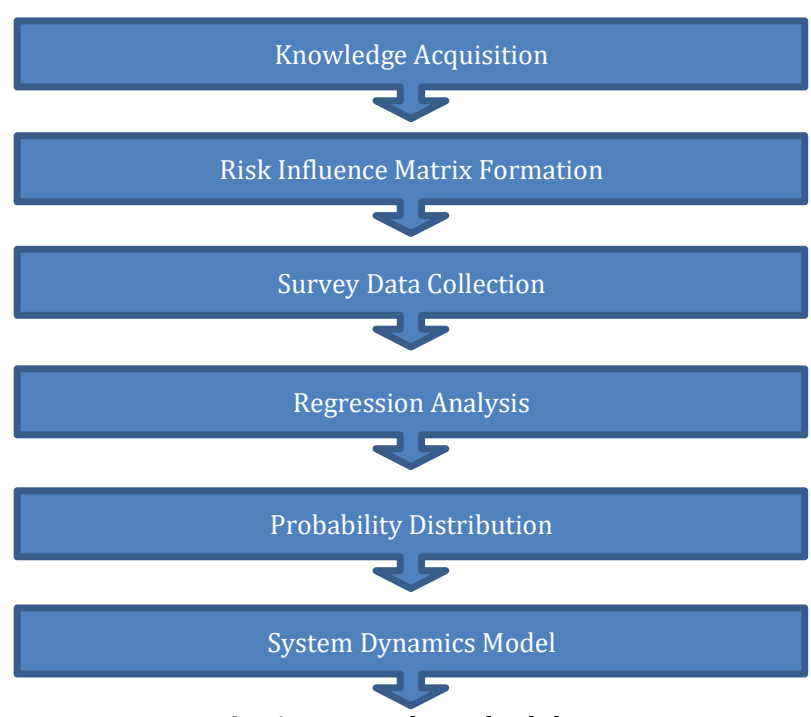

Fig. 1: Research methodology

\section{Mapping political risk factors into construction cost factors}

According to Baloi and Price (2003), any project funded by the government considered a political project, and one of the essential political risk factors for privatized infrastructure projects is uncertainty. Moreover, $\mathrm{Xu}$ et al. (2011) indicated that political risk factors have a significant impact on construction cost from estimation to the level of completion, and play a significant role in the performance of PPP projects.

The illustrated Fig. 2 indicates the impact of each political risk factor to another and indicate as well the impact of each political factor into the construction cost affecting factors. As shown in Fig. 2 , changing laws is one of the most influential risk factors. In support of that, Baloi (2002) stated some acts in law, such as design modifications, can have a huge impact on projects and considered a result of changing laws. The financial impact of changing the design of the project depends on the nature of the changes and the stage on the project construction. 
The implementation of design flexibility properties makes the major changes not possible in the stage of construction.

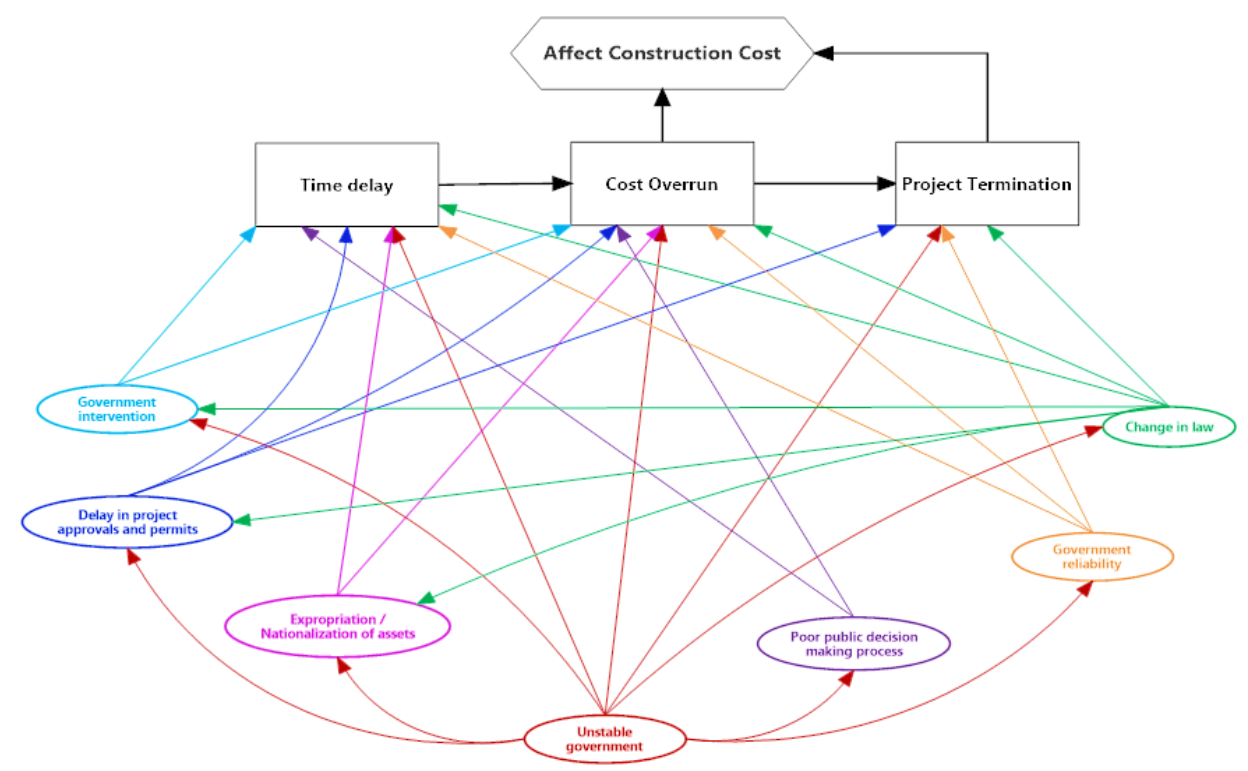

Fig. 2: Mapping political risk factors into construction cost

Besides, another important, influential factor of political risk is government intervention in terms of project administration and project supervision. Several kinds of interventions impact the progress of the PPP project, such as interfere in design, site selection, methods of construction, project operation. Moreover, the government can interfere with product sales of PPP projects by making a compulsory regulation applied and making an order for buying construction and raw materials (Xu et al., 2011). The contractor creates a specific plan to carry out the work activities, but it could be affected by the owner's interventions. Specifically, the government intervention risk factor causes a tremendous impact on project finance, so both parties need to be aware of the risk allocation

\section{Risk and system dynamic analysis}

In this research paper, the risk factors analysis implemented through series of stages starting from gathering data about risk factors and its impact on the price using the format of data collection, and then applying multiple regression analysis using SPSS to create the interdependency between the risk factors. After these two stages using Best Fit software to find the best distribution for each risk event is the next step. After this step, the fourth step is to build a risk-pricing model to determine the impact of risk factors on the risk cost and outturn unit cost. Finally, run the model to investigate the consequences variability to simulate the risk cost and outturn unit cost. Table 1 shows the Risk Matrix for Degree of Impact of Risks on Risk Cost.

\section{Analysis and ranking political risks}

The political risk factors are 10 in the category with an average weighted mean for the factors that vary from 0.1191 to 0.3057 , and the overall mean 0.2015 . Table 2 indicates that there is one risk factor (RP3) that is ranked as the highest risk impact on cost. This risk factor is indicated in Table 2 as the RP3 Poor public decision-making process resulted in a mean of 0.3057 . The responses indicate that 13 respondents $19 \%$ provided a score of very profoundly affected to the construction price. In addition, 17 respondents $25 \%$ provided a score of highly affected to construction price. As a result, the high scores of RP3 is clear evidence from professionals that it is the most influential factor affecting the construction price recognize it.

Table 1: Risk matrix for degree of impact of risks on risk cost

\begin{tabular}{cccccc}
\hline VH & 0.5583 & 0.5775 & 0.6351 & 0.6735 & 0.7119 \\
H & 0.4033 & 0.4292 & 0.5071 & 0.5590 & 0.6108 \\
M & 0.0933 & 0.1327 & 0.2510 & 0.3299 & 0.4087 \\
L & 0.0675 & 0.1080 & 0.2297 & 0.3108 & 0.3918 \\
VL & 0.0442 & 0.0858 & 0.2105 & 0.2936 & 0.3767 \\
\cline { 2 - 6 } & VL & L & M & H & VH \\
\hline
\end{tabular}

\section{Allocation of exogenous risk events based on risk cost}

The political Risk is related to a range of risk events that are emerging from issues related to government policy, taxations, etc. the ten political risk factors in this research are extracted from the literature review. Table 3 indicates that the majority of the respondents, if the political risk event is very low, low, or medium then the risk should be 
allocated to the public sector. However, the respondents allocated the RP10 to the private sector when the risk event was low and very low.

The majority of the respondents allocated RP10 to the private sector. The respondents generally suggested that if RP3-Poor public decision-making process risk was medium, which allocated it to the public sector. Table 3 shows Political risks allocation based on the level of risk price.

Table 2: Ranking of political risks (Risk likelihood and risk impact)

\begin{tabular}{|c|c|c|c|c|c|c|c|c|}
\hline \multirow{2}{*}{\multicolumn{2}{|c|}{ Risk Factor }} & \multirow{2}{*}{ Mean } & \multirow{2}{*}{$\begin{array}{c}\text { Std. } \\
\text { Deviation }\end{array}$} & \multicolumn{4}{|c|}{ Ranking } & \multirow{2}{*}{$\begin{array}{c}\text { Coefficient of } \\
\text { variation } \\
\end{array}$} \\
\hline & & & & Category & Overall & Public & Private & \\
\hline RP1 & Change in law & .1904 & .1807 & 6 & 45 & 54 & 39 & 94.8887 \\
\hline RP2 & Delay in project approvals and permits & .2880 & .1781 & 2 & 20 & 20 & 19 & 61.8158 \\
\hline RP3 & Poor public decision making process & .3057 & .1869 & 1 & 15 & 16 & 13 & 61.13675 \\
\hline RP4 & Government intervention & .1946 & .1500 & 5 & 43 & 44 & 42 & 77.05639 \\
\hline RP5 & Unstable government & .1725 & .1752 & 7 & 54 & 56 & 48 & 101.5926 \\
\hline RP6 & Government reliability & .1989 & .2134 & 4 & 39 & 49 & 37 & 107.3117 \\
\hline RP7 & Inconsistencies in government policies & .2393 & .1843 & 3 & 33 & 31 & 31 & 77.0331 \\
\hline RP8 & Strong political opposition / hostility & .1191 & .1170 & 10 & 64 & 63 & 64 & 98.24785 \\
\hline RP9 & Expropriation/nationalization of assets & .1431 & .1372 & 9 & 61 & 64 & 56 & 95.82639 \\
\hline RP10 & Inability of concessionaire & .1632 & .1404 & 8 & 59 & 60 & 50 & 86.01758 \\
\hline
\end{tabular}

Table 3: Political risks allocation based on level of risk price

\begin{tabular}{|c|c|c|c|c|c|c|}
\hline \multirow{2}{*}{ Risk Factor } & \multicolumn{2}{|c|}{$1^{\text {st }}$ priority } & \multicolumn{2}{|c|}{$2^{\text {nd }}$ priority } & \multicolumn{2}{|c|}{$3^{\text {rd }}$ priority } \\
\hline & Risk Price & Risk Allocation & Risk Price & Risk Allocation & Risk Price & Risk Allocation \\
\hline RP1 & $\mathrm{L}$ & PC & VL & $\mathrm{PC}$ & $\mathrm{H}$ & $\mathrm{SH}$ \\
\hline RP2 & $\mathrm{L}$ & PC & M & PC & M & SH \\
\hline RP3 & M & PC & $\mathrm{L}$ & PC & M & PV \\
\hline RP4 & $\mathrm{L}$ & PC & M/VL & PC & $\mathrm{L}$ & PV \\
\hline RP5 & VL & PC & $\mathrm{L}$ & PC & VL & $\mathrm{SH}$ \\
\hline RP6 & $\mathrm{L}$ & PC & VL & PC & $\mathrm{L}$ & PV \\
\hline RP7 & $\mathrm{L}$ & PC & M & PC & $\mathrm{L}$ & PV \\
\hline RP8 & VL & PC & $\mathrm{L}$ & $\mathrm{PC}$ & $\mathrm{L}$ & PV \\
\hline RP9 & VL & PC & $\mathrm{L}$ & PC & M & PV \\
\hline RP10 & $\mathrm{L}$ & PV & VL & PV & $\mathrm{L}$ & $\mathrm{PC}$ \\
\hline
\end{tabular}

It is noted that the previous studies are not aligned with the result of this study. Also, the literature includes the European bank PPP guide suggests, "in general, the private sector is better placed to assume commercial risks while the public sector is better placed to assume legal and political risks." Since in Saudi Arabia, the economy is controlled by the government, and it is the norm in other countries, if the public projects under preform the government steps in to support.

\section{System dynamics (SD) for modeling risk cost}

According to Sachs et al. (2007), most PPP projects need financial support from the government in order to sustain as a long-time investment. In this research, the political risk includes 10 risk factors identified from previous studies. Moreover, most of those risk factors interact and influence each other. When one risk event happened, it might influence the other risk factors to occur. Fig. 3 illustrates the consequences of political risks on construction unit cost and risk cost, which illustrate that poor decision making causing construction dealt, which leads to cost overrun in construction. This is in line with what is indicated in (Chan et al., 2010). This risk event also will overlap in loop 1 with delay to prevent, which means increasing the impact of other political risk events. This would create more affected circles in positive loops 5 and 6 because the risk will increase in both construction delay and construction overruns, which leads to higher risk cost and low incomes. In loop 3 the political hostility and government instability lead to more interruption and consequences related to time and cost overruns. (Delmon, 2009) suggest that the change in law risk event would impact the loop 2 expropriation risk event and lead to even more significant that impact on time and cost as well. To capture the dynamic of these consequences of political risk events, the linear multiple regressions model has been developed in this research and illustrated in Fig. 3. This model was created based on independent variability, and then subsequent variables were added to the basic model. Besides, several combinations of the variables experimented. The reason for generating multiple linear models was to map risk into the proxy variable, which might indicate the level of risk cost.

$Y=a+R p_{1} \beta_{1}+R p_{2} \beta_{2}+R p_{3} \beta_{3}+R p_{4} \beta_{4}+R p_{5} \beta_{5}+$
$R p_{6} \beta_{6}+R p_{7} \beta_{7}+R p_{8} \beta_{8}+R p_{9} \beta_{9}+R p_{10} \beta_{10}+\propto$

where, Y (Political risk impact events) is The dependent variable (Construction Cost Overrun); $\mathrm{Rp}_{1}$ is Change in law; $R p_{2}$ is Delay in project approvals and permits; $\mathrm{Rp}_{3}$ is Poor public decision making process; $\mathrm{Rp}_{4}$ is Government intervention; $\mathrm{Rp}_{5}$ is Unstable government; $\mathrm{Rp}_{6}$ is Government reliability; $\mathrm{Rp}_{7}$ is Inconsistencies in government policies; $\mathrm{Rp}_{8}$ is Strong political opposition /hostility; $\mathrm{Rp}_{9}$ is Expropriation/nationalization of assets; $\mathrm{Rp}_{10}$ is Inability of concessionaire; $\beta$ is The regression coefficient for each independent political risk variable; $\propto$ is The constant term or noise.

Construction cost overrun was used to measure the proximity risk due to political risk independent variables. An increase in $\mathrm{Y}$ value indicated the risk price that might be associated with political risks. 
Which means this is indicating a price those stakeholders willing to change in order to bear the risk. In further explanation, the increase in $\mathrm{Y}$ value could affect political risks. However, helping the risk bearer to devise strategies for managing the allocation of it.

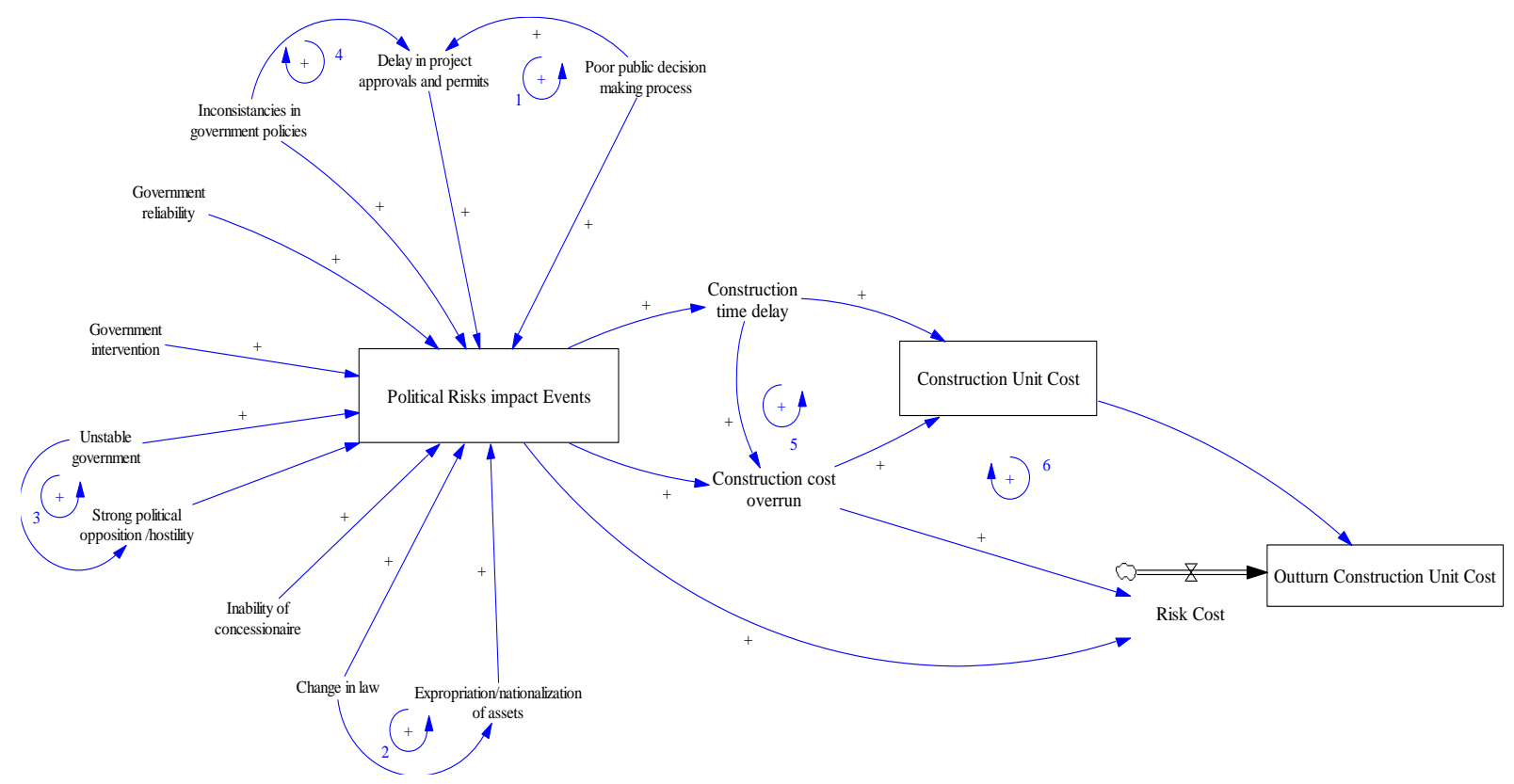

Fig. 3: Political risks sub-model

\section{Discussion and conclusion}

If the impact of risk factors is individually viewed, this could lead to underestimating the effect that may result from their interrelationships. Findings in the literature show that the interaction of risk factors can form a portfolio of the impact of risk factors greater than individual risk impact. In the absence of capturing the interaction and interdependency between risk factors comprehensively, it is not possible to create that produce results are representative of the real-world scenarios.

In this research, the magnitude of the impact of the interaction between construction risk factors is modeled using VINSIM software. It found that the relationship between the implications of risk factors is positively associated with the risk cost and with actual construction price. Consequently, as the risk impact increases affect the risk cost increases proportionally. However, beyond this point of risk impact effect, the risk costs are widely spread.

Many construction projects are completed over budget and over time. The presence of uncertainties inherent in construction projects' environment plays an essential role in construction cost overrun. This research has addressed the vital issue of interdependency between risk constructs and risk consequences. The interaction between the risk constructs is captured using multiple regression equations. Then stochastic nature of the risk constructs is modeled using simulation. This process is implemented in a system dynamics modeling environment. There is a significant need to further investigate the interaction between risk factors to increase the detection of any amplification of risk impacts due to the dynamic interdependency within system variables and between the system input variables and output outcomes.

\section{Compliance with ethical standards}

\section{Conflict of interest}

The authors declare that they have no conflict of interest.

\section{References}

Baloi D (2002). A framework for managing global risk factors affecting construction cost performance. Ph.D. Dissertation, Loughborough University, Loughborough, UK.

Baloi D and Price AD (2003). Modelling global risk factors affecting construction cost performance. International Journal of Project Management, 21(4): 261-269. https://doi.org/10.1016/S0263-7863(02)00017-0

Chan AP, Yeung JF, Yu CC, Wang SQ, and Ke Y (2010). Empirical study of risk assessment and allocation of public-private partnership projects in China. Journal of Management in Engineering, 27(3): 136-148.

https://doi.org/10.1061/(ASCE)ME.1943-5479.0000049

Delmon J (2009). Private sector investment in infrastructure: Project finance, PPP projects and risks. $2^{\text {nd }}$ Edition, World Bank Publications, Washington, USA.

Howell AR (1998). Risk allocation in the Melbourne city link project. The Journal of Structured Finance, 4(3): 11-24. https://doi.org/10.3905/jsf.4.3.24

Ke Y, Wang S, and Chan APC (2010). Risk allocation in publicprivate partnership infrastructure projects: Comparative study. Journal of Infrastructure Systems, 16(4): 343-351. https://doi.org/10.1061/(ASCE)IS.1943-555X.0000030

Kreydieh A (1996). Risk management in BOT project financing. Ph.D. Dissertation, Massachusetts Institute of Technology, Cambridge, USA.

Sachs T, Tiong R, and Qing WS (2007). Analysis of political risks and opportunities in public private partnerships (PPP) in 
China and selected Asian countries: Survey results. Chinese Management Studies, 1(2): 126-148.

https://doi.org/10.1108/17506140710758026

$\mathrm{Xu}$ Y, Yang Y, Chan AP, Yeung JF, and Cheng H (2011). Identification and allocation of risks associated with PPP water projects in China. International Journal of Strategic Property Management, 15(3): 275-294.

https://doi.org/10.3846/1648715X.2011.617867 